\title{
CrimRxiv
}

\section{Using Crowd-Sourced Data to Explore Police-Related- Deaths in the United States (2000-2017): The Case of Fatal Encounters}

Brian Karl Finch, Audrey Beck, D. Brian Burghart, Richard Johnson, David Klinger, Kyla Thomas

Published on: May 07, 2019

DOI: $10.21428 / c b 6 a b 371 . c 1 b 81 f b d$

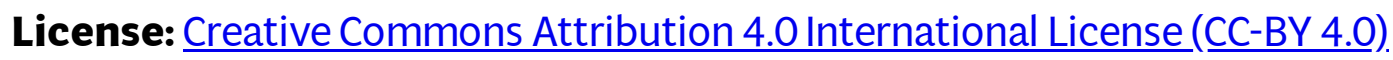


